\title{
Soluble vascular cell adhesion molecule-1 and E-selectin levels in relation to vascular risk factors and to E-selectin genotype in the first degree relatives of NIDDM patients and in NIDDM patients
}

\author{
S. Bannan, M. W. Mansfield, P.J. Grant \\ Unit of Molecular Vascular Medicine, Research School of Medicine, University of Leeds, Leeds General Infirmary, Leeds, UK
}

\begin{abstract}
Summary To investigate the metabolic and genetic associations of levels of soluble adhesion molecules, plasma levels of soluble E-selectin and vascular cell adhesion molecule- 1 were measured in 60 non-insulin-dependent diabetes mellitus (NIDDM) patients, 60 first-degree relatives of NIDDM patients and 60 control subjects, none of whom displayed clinical features of vascular disease. In addition, E-selectin A561C genotype, coding for a serine to arginine change, was determined. E-selectin levels were elevated in the patient group; 57 [52-63] (mean [95\% confidence intervals]) $\mathrm{ng} / \mathrm{ml}$, compared with both relatives; 44 [39-50] ng/ml $p=0.001$ and controls 39.5 $[36-43] \mathrm{ng} / \mathrm{ml} p=0.0001$. E-selectin levels correlated with triglycerides, tissue-plasminogen activator and plasminogen activator inhibitor-1 activity in all groups. Levels of E-selectin were related to E-selectin genotype, being higher in subjects possessing the arginine allele $(51.4 \mathrm{vs} 44.5 \mathrm{ng} / \mathrm{ml} p<0.05)$. E-selectin
\end{abstract}

levels were higher in males than females in controls (female 35 [32-39] vs male 45 [40-51] $\mathrm{ng} / \mathrm{ml} p=$ 0.004 ), and NIDDM relatives (female 38 [33-44] vs male 52 [45-61] $\mathrm{ng} / \mathrm{ml} p=0.004)$ but not in NIDDM patients where levels were similar (female 58 [49-69] vs male 56 [50-62] ng/ml, ns). There was no difference in soluble vascular cell adhesion molecule-1 levels between the three groups (control 640 [598-686] $\mathrm{ng} / \mathrm{ml}$, NIDDM relatives 634 [593-678] $\mathrm{ng} / \mathrm{ml}$ and NIDDM patients 664 [608-725] ng/ml). In controls and patients vascular cell adhesion molecule- 1 levels correlated with von Willebrand factor (vWF). The results indicate that levels of E-selectin relate to vascular risk factors in control subjects, NIDDM relatives and NIDDM patients. [Diabetologia (1998) 41: 460466]

Keywords Adhesion molecules, NIDDM, relatives, insulin resistance, vascular disease
The first degree relatives of non-insulin-dependent diabetes mellitus (NIDDM) patients are at increased risk of coronary artery disease and also have a life-

Received: 3 October 1997 and in revised form: 1 December 1997

Corresponding author: Dr. M. W. Mansfield, Unit of Molecular Vascular Medicine, Research School of Medicine, G Floor, Martin Wing, General Infirmary at Leeds, Leeds LS1 3EX, $\mathrm{UK}$

Abbreviations: VCAM-1, Vascular cell adhesion molecule-1; PCR, polymerase chain reaction; NIDDM, non-insulin-dependent diabetes mellitus; vWF, von Willebrand factor; PAI-1, plasminogen activator inhibitor-1; t-PA, tissue plasminogen activator antigen; ANOVA, analysis of variance time risk of NIDDM of up to $40 \%$ [1]. The development of these conditions appears to be predicted by the presence of features of insulin resistance and associated clustering of atherosclerotic risk in these subjects [2].

Adhesion molecules are expressed on the cellular surface of endothelium in response to inflammatory stimuli [3] and can also be detected in soluble form in the circulation. The cellular adhesion molecules E-selectin and vascular cell adhesion molecule-1 (VCAM-1) are thought to play a role in the early stages of vascular disease by facilitating the attachment of leucocytes to, and the transmigration of leucocytes through, the endothelium [4]. It is possible that circulating forms of these adhesion molecules may also have functional importance [5]. The source 
of circulating adhesion molecules is unclear although release from the endothelial cell surface may contribute $[6,7]$.

There have been reports of the elevation of circulating forms of these molecules in diabetes [3, 8-10]. It has not been determined whether these elevated levels represent early vascular damage or contribute to the increased vascular risk in patients with NIDDM and their first-degree relatives.

An A561C polymorphism in the epidermal growth factor (EGF) domain of the E-selectin gene has been described [11]. A mutation from adenine to cytosine at position 561 results in an amino acid change from serine $(\mathrm{S})$ to arginine $(\mathrm{R})$ at position 128 . In a study of young patients with angiographically established severe atherosclerosis this polymorphism was associated with a higher risk of disease [12].

The aims of this work were (1) to compare levels of circulating E-selectin and VCAM-1 in first degree relatives of NIDDM patients and control subjects and to investigate association with features of insulin resistance, (2) to examine the associations of levels of these adhesion molecules with other vascular risk factors in patients with NIDDM and (3) to examine the relationship of circulating levels of E-selectin with genotype at the E-selectin A561C polymorphism. To avoid confounding factors the relatives and control subjects were matched for age, sex and BMI and subjects with clinically evident atherosclerosis and current smokers were not selected. An older group of NIDDM patients without clinical evidence of vascular disease was also studied.

\section{Subjects and methods}

60 NIDDM patients and 60 first-degree relatives of NIDDM patients were selected from a group of subjects recruited through the Diabetes Centre at the General Infirmary in Leeds $[13,14]$. 60 control subjects without a personal or close family history of diabetes were selected from a group of subjects recruited from large employers in Leeds [13]. The relatives and controls were selected to be matched for sex, BMI and age and to be free of NIDDM, clinical atherosclerosis and current cigarette smoking. The NIDDM patients were selected to be non-smokers and to have no clinical evidence of micro- or macrovascular complications. Due to the high frequency of hypertension in NIDDM, (relating in part to a shared association with insulin resistance), this was not considered an exclusion criterion. However, data were analysed both with and without inclusion of hypertensive NIDDM subjects. Hypertension was defined as blood pressure greater than $160 \mathrm{mmHg}$ systolic or $90 \mathrm{mmHg}$ diastolic or previous diagnosis of hypertension with current treatment. All NIDDM patients were treated with oral antidiabetic therapy or diet alone. Patients receiving insulin were not included. All subjects were White Northern European and gave their informed consent according to a protocol approved by the United Leeds Teaching Hospitals (NHS) Trust Research ethics committee.

After an overnight fast of at least $10 \mathrm{~h}$ and then a $20 \mathrm{~min}$ rest, blood samples were drawn from an antecubital vein with a 19-gauge needle without venous stasis. Blood was taken into $0.9 \%$ citrate $(\mathrm{pH} 8.8)$ on ice at a ratio of 9 parts blood to 1 part citrate for measurement of E-selectin, VCAM-1, plasminogen activator inhibitor-1 (PAI-1) activity and tissue plasminogen activator antigen (t-PA) and was centrifuged at $2560 \mathrm{~g}$ at $4{ }^{\circ} \mathrm{C}$ for $30 \mathrm{~min}$. Blood taken into $0.9 \%$ citrate for the analysis of von Willebrand factor (vWF) and fibrinogen was centrifuged for $20 \mathrm{~min}$ at $2560 \mathrm{~g}$ at room temperature. Aliquots of plasma were snap frozen in liquid nitrogen and stored at $-40^{\circ} \mathrm{C}$ until assayed. Blood was also taken into lithium heparin on ice for insulin determination and lithium heparin at room temperature for plasma lipid analysis and into EDTA for $\mathrm{HbA}_{1 \mathrm{C}}$ estimation and DNA extraction.

BMI was calculated by dividing the weight in kilograms by the square of the height in meters. Systolic and diastolic blood pressure readings were taken to the nearest $2 \mathrm{mmHg}$ as the mean of three measurements with the subject seated. Both VCAM-1 and E-selectin were measured in duplicate by ELISA from R \& D Systems (Abingdon, Oxon, UK). Total immunoreactive insulin was measured by RIA (Pharmacia, Uppsala, Sweden). Cholesterol and triglycerides were determined using a Hitachi 747 autoanalyser (Boerhinger Mannheim, Mannheim, Germany) and HDL by a Hitachi 717 auto analyser (Boerhinger Mannheim) after removing chylomicrons. PAI-1 activity was measured by chromogenic assay (Spectrolyse, Biopool, Umea, Sweden) and t-PA by an ELISA (Imulyse, Biopool). vWF was measured by ELISA (Dako A/S, Denmark) and fibrinogen by the Clauss method [15]. $\mathrm{HbA}_{1 \mathrm{C}}$ was measured with a Glycomat auto-analyser (Ciba Corning, Halstead, Essex, UK) with a reference range of 4.5-6.5\%. Intra-assay and inter-assay variability were 4.8 and $7.4 \%$ respectively for E-selectin, 5.0 and $9.2 \%$ for VCAM-1, 2.5 and $3.8 \%$ at $30 \mathrm{mU} / 1$ and 4 and $15 \%$ at $8 \mathrm{mU} / 1$ for the insulin assay, $5.8 \%$ and $8.0 \%$ for PAI-1, 7.0 and $10.5 \%$ for t-PA, 2.8 and $4.7 \%$ for vWF and 2.0 and $3.5 \%$ for fibrinogen.

Determination of E-selectin genotype. Genomic DNA was extracted by a dodecyltrimethylammonium (DTAB)/cetryltrimethylammonium bromide (CTAB) method [16]. DNA was amplified by the polymerase chain reaction (PCR) in a $25 \mathrm{ml}$ reaction containing $100 \mathrm{ng} \mathrm{DNA}, 1.5 \mathrm{mmol} / \mathrm{l} \mathrm{MgCl} 2,200 \mu \mathrm{mol} / \mathrm{l}$ dNTPs, $1 \mathrm{mmol} / \mathrm{l}$ of each primer, $10 \mathrm{mmol} / \mathrm{l}$ tris $(\mathrm{pH} 8.8$ at $25^{\circ} \mathrm{C}$ ), $50 \mathrm{mmol} / 1 \mathrm{KCl}$, and $0.1 \%$ Triton $\mathrm{X}-100$. The nucleotide sequences of the primers were $5^{\prime}$-TCA TCA TGC TTT GTA TTT TCC G-3' (forward) and 5 '-GTC TCA GCT CAC GAT CAC CA-3' (reverse) which amplified a 268 base pair fragment in the E-selectin gene. The reaction was carried out for 30 cycles, with a denaturation step of $1 \mathrm{~min}$ at $94^{\circ} \mathrm{C}$, annealing for $1 \mathrm{~min}$ at $57^{\circ} \mathrm{C}$ and extension for $1 \mathrm{~min}$ at $72^{\circ} \mathrm{C}$. A cutting site for the restriction enzyme Pst1 $\left(5^{\prime}-\mathrm{CTGCA}^{\wedge} \mathrm{G}-3^{\prime}\right)$ was present in the $\mathrm{S}$ allele but not in the $\mathrm{R}$ allele due to an adenine to cytosine transition. Digestion of the PCR products was carried out with 5U Pst1 (New England Biolabs) overnight at $37^{\circ} \mathrm{C}$ yielding 219 base pair and 49 base pair fragments for the $\mathrm{S}$ allele and an uncut 268 base pair fragment for the $\mathrm{R}$ allele. The fragments were separated by electrophoresis in $1.5 \%$ agarose, and photographed over ultraviolet light after staining with ethidium bromide.

To permit use of parametric analyses the data for VCAM-1, E-selectin, insulin, triglyceride and PAI-1 were log-transformed. The results are presented as means (or geometric means) and $95 \%$ confidence intervals. Age was treated as a non-parametric variable and is presented as median (25th-75th centile). One-way analysis of variance (ANOVA) was used to detect differences between all the groups with Scheffé test used to detect significant pairwise differences. The Spearman rank test was used to estimate correlations of 
Table 1. Clinical characteristics of the three groups of subjects. Values are expressed as mean (95\% confidence intervals), $n=60$ in each group, significant $p$-values indicate higher values in the patient group compared with the relative and control groups by one-way ANOVA and Kruskal-Wallis in the case of age.

\begin{tabular}{|c|c|c|c|c|c|}
\hline & patients & relatives & controls & $p$-value & Significance \\
\hline $\operatorname{sex} M / F$ & $32 / 28$ & $28 / 32$ & $28 / 32$ & NS & \\
\hline age, years & $60.3[57.9-62.7]$ & $42.2[30.9-52.3]$ & $44.5[41.2-47.8]$ & 0.00001 & C vs $\mathrm{P} R$ vs $\mathrm{P}$ \\
\hline systolic blood pressure, $\mathrm{mm} \mathrm{Hg}$ & 144 [139.2-148.8] & 124.3 [120.3-128.4] & 118.6 [115.6-121.8] & 0.00001 & C vs $\mathrm{P} R$ vs $\mathrm{P}$ \\
\hline diastolic blood pressure, $\mathrm{mm} \mathrm{Hg}$ & $85.3[82.8-87.8]$ & 78.8 [76.2-81.4] & $79.8[77.3-82.4]$ & 0.0009 & C vs $P$ R vs $P$ \\
\hline $\mathrm{BMI}, \mathrm{kg} / \mathrm{m}^{2}$ & $29.8[28.6-31]$ & $26.9[25.9-27.9]$ & $27.2[18.3-40.1]$ & 0.001 & $\mathrm{C}$ vs $\mathrm{P} R$ vs $\mathrm{P}$ \\
\hline fasting glucose, $\mathrm{mmol} / \mathrm{l}$ & $9.6[8.8-10.4]$ & $4.9[4.8-5.1]$ & $5.0[4.9-5.1]$ & 0.00001 & $\mathrm{C}$ vs $\mathrm{P} \mathrm{R}$ vs $\mathrm{P}$ \\
\hline $\mathrm{HbA}_{1 \mathrm{c}} \%$ & $6.9[6.5-7.3]$ & $4.9[4.0-5.7]$ & $5.0[4.9-5.1]$ & 0.00001 & $\mathrm{C}$ vs $\mathrm{P} \mathrm{R}$ vs $\mathrm{P}$ \\
\hline fasting insulin, $\mathrm{mU} / \mathrm{l}$ & $21.1[18.1-24.7]$ & $9.4[8.4-10.4]$ & $7.9[7.3-8.6]$ & 0.00001 & $\mathrm{C}$ vs $\mathrm{P} R$ vs $\mathrm{P}$ \\
\hline HDL-cholesterol mmol/l & $1.1[1.0-1.2]$ & $1.3[1.2-1.4]$ & $1.3[1.2-1.4]$ & 0.003 & C vs P \\
\hline total triglyceride, $\mathrm{mmol} / \mathrm{l}$ & $2.3[1.9-2.6]$ & $1.4[1.2-1.5]$ & $1.3[1.1-1.5]$ & 0.00001 & C vs $\mathrm{P} R$ vs $\mathrm{P}$ \\
\hline PAI-I activity, U/ml & $22.6[19.1-26.8]$ & 14.1 [11.8-16.9] & $10.5[9.1-13.4]$ & 0.00001 & C vs P R vs $\mathrm{P}$ \\
\hline fibrinogen, $g / 1$ & $3.1[2.9-3.3]$ & $2.9[2.8-3.1]$ & $2.9[2.8-3.0]$ & NS & \\
\hline vWF antigen, IU/ml & $1.2[1.1-1.3]$ & $1.0[0.1-1.9]$ & $1.0[0.9-1.1]$ & 0.0008 & C vs P R vs $\mathrm{P}$ \\
\hline E-selectin, $\mathrm{ng} / \mathrm{ml}$ & $57[52-63]$ & 44 [39-50] & $39.5[36-43]$ & 0.00001 & $\mathrm{C}$ vs $\mathrm{P} \mathrm{R}$ vs $\mathrm{P}$ \\
\hline VCAM-I, ng/ml & 664 [608-725] & 634 [593-678] & $640[598-686]$ & NS & \\
\hline
\end{tabular}

VCAM-1 and E-selectin with other factors. Chi-squared testing was used to compare the genotype frequencies between the patients, relatives and control subjects. Statistical significance was taken as $p$ less than 0.05. All statistical analyses were performed with SPSS for windows version 6.1 (SPSS, Chicago, Ill., USA).

\section{Results}

The NIDDM patients were older and, as expected, had higher glucose, $\mathrm{HbA}_{1 \mathrm{C}}$ and insulin levels. Levels of triglyceride, PAI-1 and $\mathrm{vWF}$ were higher in patients as were both systolic and diastolic blood pressure, although 27 patients, 3 relatives and 6 control subjects were receiving antihypertensive therapy (Table 1).

Among the NIDDM patients levels of E-selectin and VCAM-1 were similar in subjects with and without hypertension and exclusion of hypertensive subjects did not alter the outcome of comparisons made between subject groups or sexes.

Plasma levels of E-selectin were significantly higher in the patient group compared to both other groups but not significantly so in relatives compared to control subjects (Table 1). Levels of E-selectin were higher in male than female subjects in both the control subjects (female 35 [32-39] $\mathrm{ng} / \mathrm{ml}$ vs male 45 [40-51] $\mathrm{ng} / \mathrm{ml} p=0.004$ ) and relatives (female 38 [33-44] $\mathrm{ng} / \mathrm{ml}$ vs male $52[45-61] \mathrm{ng} / \mathrm{ml} p=0.004)$ but this difference was lost in the patients (female 58 [49-69] $\mathrm{ng} / \mathrm{ml}$ vs male 56 [50-62] $\mathrm{ng} / \mathrm{ml} p=0.68)$ and these differences were not altered by adjustment for age, sex and BMI by factorial ANOVA (Fig. 1).

Consistent correlations with E-selectin were reported for PAI-1 (in control subjects, relatives and patients respectively; $r=0.32,0.28$ and 0.27 ), t-PA $(r=0.43,0.33$ and 0.29$)$ and triglyceride $(r=0.30$,

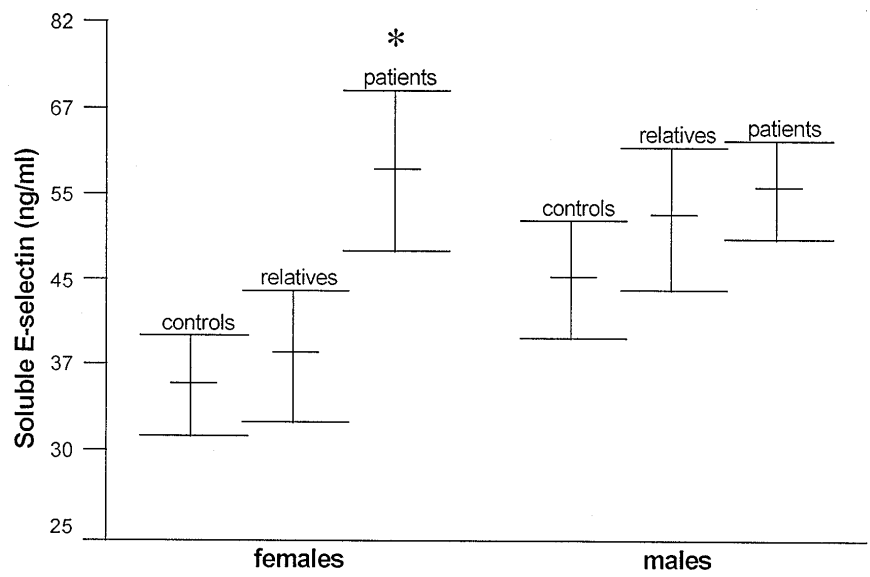

Fig. 1. Soluble E-selectin levels expressed as geometric means and $95 \%$ confidence intervals, depicting the significantly higher levels $(p=0.0001)$ of patients compared with both relatives and control subjects in females but not males

0.28 and 0.35 ). There were also inconsistent associations of E-selectin with cholesterol and fibrinogen in the control group ( $r=0.33$ and 0.29 respectively), with diastolic blood pressure and $\mathrm{VWF}$ in the relative group ( $r=0.28$ and -0.36 , respectively) and with diastolic blood pressure and insulin levels in the patient group ( $r=0.41$ and 0.45 , respectively). All correlations with $r$ greater than 0.26 were significant at $p$ less than 0.05 .

E-selectin genotype was determined in all but eight subjects in whom DNA amplification failed. Genotypes were in Hardy-Weinberg equilibrium in each group and did not differ between the three groups studied (Table 2). The less frequent $\mathrm{R}$ allele had a frequency of 0.133 . Due to the low frequency of RR homozygotes these subjects were combined with the SR heterozygotes for further analysis. 
Table 2. E-selectin genotypes in NIDDM patients, first-degree relatives of NIDDM patients and control subjects

\begin{tabular}{lllll}
\hline E-selectin genotype & SS & SR & RR & Total \\
\hline NIDDM patients & 40 & 15 & 1 & 56 \\
Relatives of NIDDM patients & 43 & 16 & 0 & 59 \\
Control subjects & 45 & 11 & 1 & 57 \\
\hline
\end{tabular}

No difference in genotype frequencies between groups. (For 8 subjects genotype could not be determined)

Table 3. E-selectin levels by E-selectin genotype

\begin{tabular}{llll}
\hline E-selectin (ng/ml) & SS & SR \& RR & $p$ \\
\hline All subjects & $44.5(41.3-47.8)$ & $51.4(45.3-58.2)$ & 0.049 \\
NIDDM patients & $51.5(45.8-58.0)$ & $72.3(60.6-86.3)$ & 0.002 \\
Relatives of & & & \\
NIDDM patients & $43.7(37.6-50.8)$ & $43.8(37.4-51.3)$ & NS \\
Control subjects & $39.7(35.7-44.1)$ & $40.3(32.2-50.4)$ & NS \\
\hline
\end{tabular}

Values shown are geometric mean (95\% confidence interval)

When all groups were combined, levels of circulating E-selectin were higher in carriers of the $\mathrm{R}$ allele than in SS homozygotes, although as shown in Table 3, this difference was found only in the NIDDM patients. In a factorial ANOVA model, levels of E-selectin remained significantly higher in $\mathrm{R}$ allele carriers $(p<0.05)$ when adjusted for sex, age, subject group, triglyceride level and two-way factorial interaction terms. The only other significant terms were subject group, sex, triglyceride and the interaction term between subject group and sex. There was no evidence of interaction between E-selectin genotype and triglyceride or PAI-1 levels in relation to E-selectin levels.

Levels of VCAM-1 were similar in all groups (Table 1) and there was no difference by gender in any group. VCAM-1 was found to correlate with vWF in the control subjects and patients $(r=0.39$ and 0.27 , respectively) and with t-PA $(r=0.29)$, triglycerides $(r=0.27)$, BMI $\quad(r=0.34), \quad$ HDL cholesterol $(r=-0.38)$ and systolic blood pressure $(r=0.38)$ in the relatives $(p<0.05$ where $r>0.26)$.

\section{Discussion}

The steps by which NIDDM causes atherosclerotic vascular disease are not entirely clear. Emphasis is shifting from elucidation of specific metabolic risk factors such as the features of insulin resistance, to an understanding of the processes occurring at the level of the vasculature and in particular the endothelial cell. E-selectin is involved in the rolling and transient association of leucocytes along the endothelium and VCAM-1 in the attachment and transmigration of leucocytes through the endothelium [17-19]. These processes are both believed to play a role in the early establishment of atherosclerotic plaques [4]. Synthesis of both E-selectin and VCAM-1 are induced rapidly by cytokines such as interleukin-1, tumour necrosis factor and lipopolysaccharide [19], and may therefore be produced in response to inflammation and other disease processes [10]. There is also evidence that the soluble forms of adhesion molecules may have important biological activities. Both E-selectin and VCAM-1 have been shown to have chemotactic activity in vitro and angiogenic activity in rat cornea [5]. Although it is unclear how these activities demonstrated in vitro and animal models may relate to the pathophysiology of atherosclerosis, it does indicate that both endothelial and soluble forms of E-selectin and VCAM-1 may be involved in the early stages of atherogenesis and possibly before the onset of observable clinical symptoms.

Alternatively, the circulating forms of adhesion molecules E-selectin and VCAM-1 may have no biological function in vivo and act simply as a markers of pre-existing vascular damage or of the presence of other vascular risk factors. Finally, they may reflect some causal involvement of cell-bound adhesion molecules in the atherogenic process, which are later shed into the circulation.

We found a consistent relationship of levels of Eselectin to other vascular risk markers, particularly triglyceride, PAI-1 and t-PA levels. As PAI-1 and tPA are synthesised in increased quantity by atherosclerotic arteries [20] this would support the notion that elevated circulating levels of E-selectin reflect pre-existing vascular disease. The pattern of association of E-selectin with triglyceride but not insulin levels (except in the NIDDM patients) and no clear correlation with HDL-cholesterol and body mass index suggests that circulating levels of E-selectin cannot be considered a novel feature of the syndrome of insulin resistance.

In this study there was no association between levels of soluble E-selectin and markers of glycaemic control; $\mathrm{HbA}_{1 \mathrm{C}}$ and fasting glucose, in any of the three study groups. This concords with one previous study in NIDDM [21] but is not in accordance with the studies of Cominacini et al. which have demonstrated a strong association with $\mathrm{HbA}_{1 \mathrm{C}}[9,22]$ and Fasching et al. who found a weaker association with $\mathrm{HbA}_{1 \mathrm{C}}$ [23]. There is also conflicting data in IDDM with some studies showing association of E-selectin with $\mathrm{HbA}_{1 \mathrm{C}}[9,24]$ and others not [25]. This confusing picture of apparently contradictory results may be accounted for in part by differences in degree of glycaemic control. In our study NIDDM subjects showed mean $\mathrm{HbA}_{1 \mathrm{C}}$ levels $1.9 \%$ above those in control subjects whereas in the study of Fasching et al. the difference was $3.2 \%$ and in the larger study by Cominacini et al., the association between levels of E-selectin and $\mathrm{HbA}_{1 \mathrm{C}}$ was lost when glycaemic control was im- 
proved [22]. The findings of an in vitro study are also at variance with the positive association of glycaemia and E-selectin levels. Human umbilical endothelial cells cultured in a high glucose concentration medium showed reduced cytokine-stimulated expression of Eselectin compared to cells cultured in normal glucose medium [26].

Alternatively, it has been suggested that the association between glycaemia and E-selectin may actually reflect an underlying association with other metabolic factors such as the oxidation of LDL-cholesterol or the formation of advanced glycation endproducts $[22,27]$. As no measurement was made of markers of oxidative stress in the current study we have been unable to further investigate this possibility.

In keeping with previous studies we found increased levels of soluble E-selectin in subjects with NIDDM. Although the NIDDM subjects were older than both control and relative groups, there was no evidence within each group of variation of E-selectin levels with age. This suggests that the elevated levels of E-selectin can be attributed to some feature of NIDDM per se, whether this be metabolic or related to its therapy, or complications such as subclinical arterial disease.

Despite being at increased risk of both NIDDM and symptomatic atherosclerosis, the first-degree relatives of NIDDM patients showed levels of E-selectin which were not significantly elevated compared to age matched controls. Therefore these findings alone cannot support a role for soluble E-selectin in the early development of atherosclerosis. As the NIDDM relatives in this study were selected to be matched for body mass index with the control subjects, and because levels of E-selectin correlate with some (but not all) features of insulin resistance, it is possible that by not including relatives with a greater degree of insulin resistance, levels of E-selectin in a representative sample of NIDDM relatives have been underestimated.

As has been demonstrated previously, levels of Eselectin were higher in male control subjects than female control subjects [28-30] and the same was true of NIDDM relatives. However, in the NIDDM patients E-selectin levels were no different in males and females. This interaction between NIDDM and gender for levels of E-selectin mimics the pattern of vascular risk seen with the development of NIDDM, that is that the presence of NIDDM causes loss of the protection from vascular risk associated with being female. However, albeit an interesting finding, as this study is cross-sectional it cannot answer whether E-selectin contributes to the sex-specific increase in vascular risk seen in NIDDM.

In this paper we have reported a novel association of circulating levels of soluble E-selectin to E-selectin A561C genotype. This association was found only in the NIDDM patient group, who had the highest levels of E-selectin and vascular risk markers and who probably had a high rate of sub-clinical vascular disease. Such a finding implicates an involvement of some aspect of NIDDM with increased levels of E-selectin in relation to the E-selectin genotype. Again, this factor may be metabolic or relate to the complications or treatment of diabetes. As E-selectin expression is increased by inflammatory markers it is possible that this cytokine-mediated expression is modulated by E-selectin genotype. Increased expression of E-selectin may theoretically lead to increased white blood cell recruitment by the endothelium and accelerated atherosclerosis. If further studies in larger subject groups can confirm our findings, it would suggest a mechanism accounting for the earlier finding of an association of this polymorphism with a history of ischaemic heart disease [12], as well as supporting the notion that E-selectin levels may have some role in the development of symptomatic atherosclerosis.

In contrast to our findings for E-selectin, we could detect no difference in levels of soluble VCAM-1 between the three study groups. Previous studies of levels of VCAM-1 in diabetes have given inconsistent results, some finding increased levels in NIDDM [21, 23 ] and others finding no increase [9]. There is also evidence that levels of VCAM-1 are increased in both NIDDM and IDDM with the presence of diabetic retinopathy or nephropathy $[8,24]$. Steiner et al. who examined a similar group of NIDDM patients to ours, with no evidence of symptomatic vascular disease, found increased levels of circulating VCAM-1 compared to control subjects [21]. In that study the same assay was used and values for VCAM-1 were similar in the patients but lower in the control subjects than we found. In addition the control subjects studied were of similar age to the patients and older than the control subjects in our study. This may account for the differing results between the two studies although we could not find any association between age and levels of circulating VCAM-1. Indeed, where age has been found to correlate with levels of soluble VCAM-1 the association has been positive $[23,29]$. The study reported by Steiner et al. included smokers whereas we excluded smokers and this may point to some interaction between cigarette smoking and diabetes with regard to levels of VCAM-1.

We did confirm the previously reported association of levels of VCAM-1 and vWF [21]. Levels of vWF appear not to show a close relationship with insulin resistance as do other haemostatic risk markers, and to date have been shown to predict vascular outcome only in the presence of pre-existing clinically detectable vascular disease [31, 32]. It is possible that levels of soluble VCAM-1 may act as a risk marker in this sub-group, however subjects with clini- 
cally evident microvascular or macrovascular disease were excluded from this study. The absence of association between levels of VCAM-1 and $\mathrm{HbA}_{1 \mathrm{C}}$, as a measure of glycaemic control, is in keeping with the in vitro observation that expression of VCAM-1 was unchanged in human umbilical vein endothelial cells cultured in increased glucose concentration [26].

In a study of first degree relatives of NIDDM patients matched for age and sex with healthy control subjects and of NIDDM patients without evidence of macrovascular disease or retinopathy, we found that levels of soluble E-selectin relate to vascular risk in that (1) they are associated with other vascular risk markers (PAI-1, t-PA and fasting triglyceride level) and (2) E-selectin levels resemble the pattern of vascular risk by sex seen in control subjects and NIDDM patients. In addition we found a novel relationship between levels of E-selectin and genotype at an A561C polymorphism in the E-selectin gene in NIDDM patients. If confirmed, this latter association would provide a mechanism to test the possible relationship of E-selectin levels with the development of vascular disease in NIDDM. In contrast, levels of VCAM-1 were similar in NIDDM patients, relatives and control subjects.

Acknowledgements. The authors wish to acknowledge the support of the British Heart Foundation and the Children's Heart Surgery Fund.

\section{References}

1. Kobberling J, Tillil H, Lorenz HJ (1985) Genetics of type 2A and type 2B diabetes mellitus. Diabetes Res Clin Pract 11: 311

2. Haffner SM, Stern MP, Hazuda HP, Mitchell BD, Patterson JK (1988) Increased insulin concentrations in nondiabetic offspring of diabetic parents. N Engl J Med 319: 1297-1301

3. Gearing AJH, Hemingway J, Pigott R, Hughes J, Rees AJ, Cashman SJ (1992) Soluble forms of vascular adhesion molecules, E-selectin, ICAM-1, and VCAM-1: pathological significance. Ann NY Acad Sci 667: 324-331

4. Campbell JH, Campbell GR (1994) Cell biology of atherosclerosis. Hypertension 12:S129-S132

5. Koch AE, Halloran MM, Haskell CJ, Shah MR, Polverini PJ (1995) Angiogenesis mediated by soluble forms of E-selectin and vascular cell adhesion molecule-1. Nature 376: 517-519

6. Pigott R, Dillon LP, Hemingway IH, Gearing AJH (1992) Soluble forms of E-selectin, ICAM-1 and VCAM-1 are present in the supernatants of cytokine activated cultured endothelial cells. Biochem Biophys Res Commun 187: 584-589

7. Newman W, Beall LD, Carson CW et al. (1993) Soluble Eselectin is found in supernatants of activated endothelial cells and is elevated in the serum of patients with septic shock. J Immunol 150: 644-654

8. Schmidt AM, Crandall J, Hori O, Cao R, Lakatta E (1996) Elevated plasma levels of vascular cell adhesion molecule1 (VCAM-1) in diabetic patients with microalbuminuria: a marker of vascular dysfunction and progressive vascular disease. Br J Haematol 92: 747-750

9. Cominacini L, Fratta Pasini A, Garbin U et al. (1995) Elevated levels of soluble E-selectin in patients with IDDM and NIDDM: relation to metabolic control. Diabetologia 38: $1122-1124$

10. Gearing AJH, Newman W (1993) Circulating adhesion molecules in disease. Immunology Today 14: 506-512

11. Wenzel K, Hanke R, Speer A (1994) Polymorphism in the human E-selectin gene detected by PCR-SSCP. Hum Genet 94: 452-453

12. Wenzel K, Ernst M, Rohde K, Baumann G, Speer A (1996) DNA polymorphisms in adhesion molecule genes - a new risk factor for early atherosclerosis. Hum Genet 97: 15-20

13. Mansfield MW, Heywood DM, Grant PJ (1996) Circulating levels of factor VII, fibrinogen, and von Willebrand factor and features of insulin resistance in first degree relatives of patients with NIDDM. Circulation 94: 2171-2176

14. Mansfield MW, Heywood DM, Grant PJ (1996) Sex differences in coagulation and fibrinolysis in white subjects with non-insulin-dependent diabetes mellitus. Atherioscler Thromb Vasc Biol 16: 160-164

15. Marbet GA, Duckert F (1992) Fibrinogen. In Jespersen J, Bertina RM, Haverkate F (eds) ECAT assay procedures. A manual of laboratory methods. Kluwer, Dordrecht, Netherlands. pp 47-55

16. Mansfield MW, Stickland MH, Carter AM, Grant PJ (1994) Polymorphisms of the plasminogen activator inhibitor- 1 gene in type 1 and type 2 diabetes and in patients with diabetic retinopathy. Thromb Haemost 71: 731-716

17. Carter AM, Grant PJ (1997) Vascular homeostasis, adhesion molecules and macrovascular disease in non-insulin dependent diabetes mellitus. Diabetic Med 14: 423-432

18. Schleiffenbaum B, Fehr J (1996) Regulation and selectivity of leukocyte emigration. J Lab Clin Med 127: 151-168

19. Chapman PT, Haskard DO (1995) Leukocyte adhesion molecules. British Medical Bulletin 51: 296-311

20. Schneiderman J, Sawdey MS, Keeton MR et al. (1992) Increased type 1 plasminogen activator inhibitor gene expression in atherosclerotic human arteries. Proc Natl Acad Sci USA 89: 6998-7002

21. Steiner M, Reinhardt KM, Krammer B, Ernst B, Blann AD (1994) Increased levels of soluble adhesion molecules in type 2 (non-insulin-dependent) diabetes mellitus are independent of glycaemic control. Thromb Haemost 72: 979-984

22. Cominacini L, Fratta Pasini A, Garbin U et al. (1997) E-selectin plasma concentration is influenced by glycaemic control in NIDDM patients: possible role of oxidative stress. Diabetologia 40: 584-589

23. Fasching P, Waldhäusl W, Wagner OF (1996) Elevated circulating adhesion molecules in NIDDM - potential mediators in diabetic macroangiopathy. Diabetologia 39: 1242-1244

24. Olson JA, Whitelaw CM, McHardy KC, Pearson DWM, Forrester JV (1997) Soluble leucocyte adhesion molecules in diabetic retinopathy stimulate retinal capillary endothelial cell migration. Diabetologia 40: 1166-1171

25. Kopp H, Krugluger W, Hopmeier P, Schernthaner G (1997) Soluble selectins in IDDM: Possible association with lipids. Diabet Med 14: 991-992

26. Baumgartner-Parzer SM, Wagner L, Pettermann M, Gessl A, Waldhäusl W (1995) Modulation by high glucose of adhesion molecule expression in cultured endothelial cells. Diabetologia 38: 1367-1370

27. Cominacini L, Garbin U, Fratta Pasini A, Lo Cascio V (1996) Increased levels of plasma ELAM-1, ICAM-1 and 
VCAM-1 in NIDDM: possible role of oxidised LDL. Diabetologia 39: 1244

28. Jilma B, Eichler HG, Breiteneder H et al. (1994) Effects of 17 beta-estradiol on circulating adhesion molecules. J Clin Endocrinol Metab 79: 1619-1624

29. Blann AD, Daly RJ, Amiral J (1996) The influence of age, gender and $\mathrm{ABO}$ blood-group on soluble endothelial-cell markers and adhesion molecules. $\mathrm{Br} \mathrm{J}$ Haematol 92: 498-500

30. Jilma B, Dirnberger E, Eichler HG, Kapiotis S (1996) Sex differences in circulating P-selectin, E-selectin and thrombomodulin. Br J Haematol 95: 575-576
31. ECAT Angina Pectoris Study Group (1993) ECAT angina pectoris study: baseline associations of haemostatic factors with extent of coronary arteriosclerosis and other coronary risk factors in 3000 patients with angina pectoris undergoing coronary angiography. Eur Heart J 14: 8-17

32. Catto A, Carter AM, Barrett J, Bamford J, Grant PJ (1997) von Willebrand factor and factor VIII:C in acute cerebrovascular disease: relationship to stroke subtype and mortality. Thromb Haemost 77: 1104-1108 